\title{
ERNST BLOCH: CRÍTICA SALVADORA DA RELIGIÃO ${ }^{1}$
}

Francesca Vidal ${ }^{2}$

\begin{abstract}
Resumo:
"Apenas um ateu pode ser um bom cristão [...]", declara o filósofo Ernst Bloch em seu livro Ateísmo no cristianismo. Como ele chega a uma tal tese? Que representação de messianismo marca a sua filosofia da esperança? O texto mostra como Bloch quer liberar as motivações rebeldes do religioso a fim de que possam ser explicitados os seus conteúdos de esperança. Também deixa claro por que o autor presume que o ateísmo já está ativo no próprio cristianismo.
\end{abstract}

Palavras-chave: Religião; escatologia; messianismo; esperança e utopia.

\section{ERNST BLOCHS RETTENDE RELIGIONSKRITIK}

\section{Zusammenfassung:}

"Nur ein Atheist kann ein guter Christ sein [...]" erklärt der Philosoph Ernst Bloch in seinem Buch Atheismus im Christentum. Wie kommt er zu einer solchen These, welche Vorstellung vom Messianismus prägt seine Philosophie der Hoffnung? Der Text zeigt, wie Bloch die rebellischen Motive des Religiösen freilegen will, damit die Hoffnungsinhalte herausarbeitet und macht deutlich, warum er davon ausgeht, dass Atheismus im Christentum selbst wirksam ist.

Stichwörter: Religion, Eschatologie, Messianismus, Hoffnung, Utopie.

Um título reconhecidamente difícil, pois diz, por um lado, que o filósofo Ernst Bloch efetua uma crítica à religião, mas, por outro, afirma, simultaneamente, que essa crítica seria uma que salva a religião. Mas salvar do quê? A resposta Bloch oferece com sua afirmação: "Somente um ateu pode ser um bom cristão, [...] somente um cristão pode ser um bom ateu" (Bloch, 1985, p. 24). Antecipadamente pode ser presumido que, com salvar a religião, Bloch indica que pretende evitar que ela seja "útil à ideologia da reação autoritária” (Bloch, 2006a, p. 277) e, em contraposição a isso, quer liberar intencionalmente seus conteúdos de esperança. A

1 Título original: Ernst Blochs rettende Religionskritik. Trata-se de um trabalho apresentado no Evento Hoffnung, Utopie, Apokalypse - Ernst Bloch und die Religion (Esperança, Utopia, Apocalipse - Ernst Bloch e a religião), promovido pela Academia Católica de Berlim, em março de 2020. A palestra pode ser acessada em https://www.katholische-akademie-berlin.de/veranstaltung/ernst-blochs-rettende-religionskritik/. Tradução, Rosalvo Schütz, professor de Filosofia da Universidade Estadual do Oeste do Paraná (UNIOESTE). Bolsista de produtividade do CNPq. A tradução foi realizada durante pós-doutorado em Filosofia na Pontifícia Universidade Católica do Rio Grande do Sul entre 2019 e 2020 (N.T.).

2 Presidenta da Sociedade Internacional Ernst Bloch e Integrante do Instituto para Design Science da Universidade de Ciências Aplicadas de Munique/Alemanha. Docente permanente da Universidade de Koblenz/Landau Alemanha. Currículo vitae: https://www.rlp-forschung.de/public/people/Francesca_Vidal/cv (N.T.). 
crítica pretende libertar tanto de um Deus criador quanto de um Deus celeste, rumo ao seguinte pensamento:

\begin{abstract}
Fé é unicamente a voltada pra o reino de Deus messiânico - sem Deus. Em consequência disso, o ateísmo é tão pouco inimigo da utopia religiosa que constitui o pressuposto desta: sem o ateísmo o messianismo não tem lugar. A religião é superstição sempre que não é aquilo que ela gradativamente logrou significar nas suas manifestações históricas, em conformidade com seu conteúdo intencional válido: a mais incondicional das utopias, a utopia do incondicional (Bloch, 2006a, p. 283).
\end{abstract}

Reino sem Deus é, por um lado, o reino de Deus jesuânico, mas, por outro lado, é também o reino da liberdade ou, expresso de outra forma, um mundo que seja adequado ao ser humano, de modo que possa ser o seu lar/pátria (Heimat). "Lar/pátria significa uma apreensão humanizada, naturalizada e camarada do mundo, no qual os seres humanos possam pensar e agir de modo diferente daquele que hoje agem e pensam" (Koch, 2012, p. 168) ${ }^{3}$, pois, ainda que todas as utopias sociais, inclusive as da religião, indiquem um caminho, a entrada no Eschaton permanece, ainda assim, não mediatizada, um "salto total para fora de tudo o havido até ali" (Bloch, 2005, p. 201).

Justamente essa vontade de reconstruir o mundo na forma de um lar/pátria (Heimat) enfatiza o fator subjetivo, pelo qual, segundo Elke Kruttschnitt, histórica e factualmente, o cristianismo, para Bloch, é

[...] simplesmente o pressuposto adequado para o bom ateísmo; pois apenas o cristianismo trouxe ao mundo, por meio da estrutura das intenções religiosas do reino, a ideia de um reino. Essa intenção religiosa do reino, no entanto, envolve eo ipso aquele bom ateísmo referido por Bloch (1993, p. 386).

Sua análise da religião judaica e cristã equivale à análise de seus conteúdos de esperança utópicos e escatológicos, a fim de poder herdá-los para o aquém futuro. Com a ajuda de sua hermenêutica subversiva, se empenha em explicitar as motivações rebeldes do religioso. Para ele, portanto, não se trata do sentido divino, mas de trazer o ser humano para o centro. Traz à tona o que há de secular sob o teológico e que seja significativo para o aquém, para o desenvolvimento histórico e social.

Quando perguntado por que encontra isso justamente na religião, como, por exemplo, na entrevista televisiva com Iring Fetschem, em 1967, assim responde:

3 Quando disponíveis edições brasileiras, as referências são feitas em conformidade com elas ou são traduzidas diretamente, mantendo-se a referência da obra original citada (N.T.).

\begin{tabular}{|l|l|l|l|c|}
\hline Govista Qialectus & Ano 10 & n. 21 & Janeiro - Abril 2021 & p.69-83 \\
\hline
\end{tabular}




\begin{abstract}
Eu tomei gosto pelo cristianismo primitivo re-compreendido só bem mais tarde, por meio do mundo de Thomas Münzer, através de Dostojewskij, Tolstoi, portanto, por meio da função rebelde que teve. Algo que tem muito a ver com filosofia, embora tenha sido completamente esquecido pela filosofia catedrática da segunda parte do século XIX, de modo que este contato em dupla face entre uma teologia cheia de má consciência, movimentada, pensativa e uma filosofia na vinculante categoria originária da esperança não é surpreendente. [...] Mas teriam as guerras camponesas e as guerras albigenses, etc., sido possíveis com o livro das religiões egípcias ou babilônicas, com Ammon-Re, Marduck, Moloch ou Zeus ou Júpiter, o qual também pregou Prometeu a pedras (com o que eu avento a paciência da cruz, que já estava aí também anteriormente mas de forma alguma se tornou tão famosa enquanto uma prova de paciência)? Apenas com aquilo que está escrito na bíblia isso foi possível (Bloch, apud Weigand; Wetz, 1983, p. 38 ss.) ${ }^{4}$.
\end{abstract}

A ênfase dada ao cristianismo, muitas vezes, levou a questionamentos quanto à posição de Bloch em relação ao cristianismo e também ao judaísmo, chegando, por vezes, a ser indicado como um filósofo judeu. Mas justamente isso o próprio Bloch negou claramente e, com o avanço da idade, a pergunta ia sendo rejeitada até mesmo irritadamente. Ele mesmo se considerava um filósofo europeu de língua alemã e afastava de si essa declaração com a indicação de que não gostaria de que sua obra fosse concebida como sendo teologia judaica, como teria acontecido com Walter Benjamin na interpretação dada por Gershom Scholem. Não se pode negar, no entanto, de que justamente as terríveis experiências da I Guerra Mundial levaram Bloch a se ocupar com o messianismo judaico e cristão, para, em sua filosofia da esperança, tomar a ânsia de retorno ao lar de um modo universal, orientando-a para o futuro e ampliando-a. Entretanto, mesmo sem nunca negar sua origem judaica, o messianismo judaico será apenas uma fonte dentre muitas. Mesmo assim ele enfatiza essa sua origem judaica justamente por motivos políticos. Algo como o que escreveu a Johan Wilhelm Muehlon, referindo-se à frase antissemita escrita por Hugo Ball ${ }^{5}$, num editorial de 22 de novembro de 1918:

4 Essa conversa sobre Ernst Bloch e a teologia também pode ser vista no You Tube: https://www.youtube.com/watch?v=T4oXNBm29jA\&list=PL5rv0LxqofNovSyM6unMo1O2q6DyR4Fg\&inde $\mathrm{x}=14 \& \mathrm{t}=0 \mathrm{~s}$.

5 Trata-se do artigo Die Umgehung der Instanzen (O desvio das instâncias) onde a frase final de Ball (1918, p. 369), que indignou Bloch, era a seguinte: "Se envia israelitas não nacionalistas à frente, a fim de alcançar uma liquidação mais vantajosa possível, também isso é falso. O chão de uma república israelita é o país elogiado, mas não a Alemanha. Nós gostamos de trabalhar com estes senhores, contanto que se confessem inequivocamente para com o fato moral. A lenda do povo escolhido está derrotada. O Velho Testamento está derrotado, Berlim não é mais Sinai. Nós queremos uma nação alemã, uma república alemã, nós queremos uma Assembleia Nacional alemã, que desabone os fazedores de negócios e oportunistas e que se declare a favor de uma nação grande e verdadeiramente refinada. Só, e somente assim, nós ganharemos de volta a confiança do mundo". Citados por Ernst Bloch na publicação, organizada por Karola Bloch, das cartas de Ernst Bloch de 1903 até 1975 (Bloch, 1985a, p. 235, FN 4).

\begin{tabular}{|l|l|l|l|l|}
\hline Q Povista Dialectus & Ano 10 & n. 21 & Janeiro - Abril 2021 & p.69-83 \\
\hline
\end{tabular}




\begin{abstract}
Eu escrevi imediatamente para Ball, de que seu tipo de antissemitismo é escandaloso; pouco importando como é pensado (eu conheço as aprofundadas e, como muitas vezes, encurtadas conexões). Ball sabe exatamente [...] que eu sou um judeu totalmente consciente da raça e de que me orgulho do meu povo antigo e misterioso, e de que estou em casa nas melhores partes do sangue judaico e nas suas grandes tradições religiosas (Bloch, 1985a, p. 232).
\end{abstract}

Sempre de novo irá enfatizar que a expulsão/perseguição (Vertreibung) aos judeus equivale à expulsão (Austreigung) do espírito e da cultura. Nisso sua confissão ao judaísmo é sempre também uma tomada de posição em relação aos desenvolvimentos de seu tempo, na qual os seres humanos são tornados judeus, por meio da estigmatização. Ademais, mesmo que Bloch jamais tenha negado a sua origem judaica, ele se via enquanto [judeu] assimilado e, de modo totalmente autoevidente, como um ateu. Já como estudante secundarista, aos 13 anos, em Ludwigshafen, escreveu, em 1898, um tratado filosófico com o título O universo à luz do ateísmo. Um tratado em caderno de escola, em relação ao qual ele próprio mais tarde evidentemente se manifestou autocriticamente, dizendo inclusive que nem ao menos sabia como pronunciar adequadamente a palavra Atheist (ateu) e, por isso, ter falado de Atheisten.

Por toda vida, Bloch se concebia enquanto um ateu. Alguém que, na tradição de Hegel, Feuerbach, Marx, Nietzsche e da moderna ciência da natureza, escreve, em sua obra principal, Princípio Esperança: “A existência de Deus, sim, Deus de modo geral como um ente é superstição" (Bloch, 2006a, p. 283), mas que, simultaneamente, em vez de negar os significados das religiões, os destaca e vê no seu conhecimento algo especial e fundamental para o conhecimento da cultura. Em suas Preleções Leipziguianas, afirma que quem não estudou a Bíblia não pode entender toda a cultura alemã:

\footnotetext{
Não se pode entender o Gótico, a Idade Média, Dante, Rembrandt, Händel, não se pode entender Bach sem entender a Bíblia. Sim, mas o que então na realidade ainda se entende? A condição insuportável, o ser criado barbaramente, o estar parado em frente à paixão de São Mateus como uma vaca em frente ao portão do celeiro, observando-a como se se tratasse da Vitzlipuzli mexicana, essa condição insuportável precisa ter um fim (Bloch,1985f, p. 451).
}

Importante é a sua pergunta: o que propriamente (eigentlich) ainda se entende, pois este propriamente é decisivo para ele. Para poder conhecer o potencial imanente e utópico de todas as expressões da cultura humana, é preciso saber que ele está em ação justamente também na religião. O Novo e o Velho testamentos são, por isso, textos filosóficos e sociais fundamentais, para Bloch, que indicam para o futuro. Dito de outro modo: para ele, trata-se da exposição dos conteúdos utópicos da Bíblia. Por isso ele se tornará tanto um leitor crítico 
quanto salvador que, mesmo enfatizando que os textos reunidos pela posterior equipe de redação, como Sagradas Escrituras, serviram às classes dominantes, enfatiza também que estas, com isso, deturparam a mensagem propriamente dita da Bíblia. Nas Preleções Leipziguianas, Bloch quer aproximar os estudantes desse modo crítico de ler a Bíblia, a fim de atualizar seu potencial sociorrevolucionário:

Há uma frase que aparece muitas vezes na Bíblia: 'Os filhos de Israel resmungavam (murrten)'. Resmungar, uma bela palavra-Lutero. Eu gostaria de contar esta história subterrânea bíblica, a subversiva, plebeia, rebelde, revolucionária, nacionalrevolucionária. Que tal isso? E por que a Bíblia pôde se tornar o livro-base das guerras camponesas alemãs? Nos chamamentos de Thomas Münzer vocês mal e mal encontrarão uma frase que não contenha uma citação da Bíblia, e não apenas em Thomas Münzer, mas também em outros (Bloch, 1885e, p. 452).

Em 1967, na conversa televisiva com Iring Fetscher, Bloch afirma, na mesma linha, que estaria a procurar "a Bíblia subterrânea, o resmungar (Murren) dos filhos de Israel e extrair, a despeito das falsificações e deturpações empreendidas pela teocracia e pelo clero em todos os tempos, a rebelião contra o lá em cima teológico e político" (Bloch apud Moltmann, J; Metz, J.B., 1983, p. 38 ss.).

Para Bloch, por meio da leitura do texto bíblico subterrâneo, o verdadeiro cristão se torna ateu, e é por isso que Heiko Hartmann define o ateísmo de Bloch como

\begin{abstract}
negação da existência de um Deus pessoal predisponente, transcendente, que guia a história do mundo. Ateísmo para ele tem o mesmo significado que humanização das esferas e poderes transcendentes, que na história muitas vezes foram usados ideologicamente, pela classe dominante, enquanto instrumentos de opressão e intimidação. Bloch busca recuperar o divino no humano sem, no entanto, permanecer na redução antropológica de Deus realizada por Feuerbach, mas buscando o potencial sócio-revolucionário, excedente, da religião, que contribua para a estruturação de um processo histórico em direção a um reino da liberdade e da humanidade. Com isso ele procura iluminar de modo renovado esse potencial e o tornar produtivo no sentido da utopia concreta (2012, p. 38).
\end{abstract}

Decisivo nisso é que, para Bloch, não se trata de explicar a sua negação de um ser transcendente, mas, antes, de provar que o ateísmo atua no interior da própria religião, de que há utopia ateísta ativa no próprio cristianismo. Na obra Herança dessa época, isso o leva a uma declaração contra a Igreja: "Deus, no entanto, ama mais um único ateu sincero, que saiba o que isso significa, do que a milhares desses crentes" (Bloch, 1985b, p. 408), no que alude ao fato de que um ser humano que procura consolo "compensador no além" tende muito facilmente a ratificar as condições sociais do presente. 
Porém, quando o além quer abalar-se sobre a terra e a interioridade para a exterioridade, aí simplesmente surge, em vez de ópio, um material explosivo sem igual no fator subjetivo, uma vontade para o céu sobre a terra [Wille zum Himmel auf Erden] (Bloch, 1985b, p. 153).

Aqui Bloch se refere ao teólogo medieval Joachim di Fiore, cujos escritos, embora não tenham indicado um caminho para a mudança, teriam ativado a vontade para tal. No chiliasmo à la Joachim, o ateísmo se lhe faz conhecer de modo especial, pois vê aí o reino de Cristo descrito num aquém, que será realizado se esse mundo do aquém tiver se tornado um mundo novo.

No Prefácio ao Ateísmo no cristianismo, Bloch esclarece o que originalmente significa Atheoi: era a indicação para aqueles que recusavam os deuses dominantes na corte de Nero e, por isso, se tornavam mártires; portanto, era um conceito para cristãos. É nesse sentido que procura utopias ateístas no cristianismo, uma vez que não quer simplesmente livrar-se da religião, mas mostrar expressamente que se trata de salvar seu conteúdo utópico efetivo.

Bloch é um ateu convicto, porém fala do desejo

de redenção em relação à maldade, vazio, morte e mistério, rumo a uma comunidade com os santos, de uma virada de todas as coisas em direção ao paraíso; sempre e em todo lugar - o apocalipse é o a priori de toda política e cultura, que mereça ser assim chamada (Bloch, 1985c, p. 341).

Bloch é ateísta a tal ponto de se contrapor veementemente a um falso desencantamento do mundo. Quando fala de religião, não é para desmascará-la, mas sim para herdar sua potência emancipatória, para expor ser material utópico a fim de torná-lo diretamente fértil para um futuro humano. No Espírito da utopia, formula isso numa perspectiva tão livre que facilmente pode passar a impressão de que se esteja lendo um escrito esotérico, o que não torna esse escrito algo fácil para leitores e leitoras atuais. Sua reivindicação se torna mais compreensiva na interpretação da história de Jó em Ateísmo no cristianismo (1985, p. 148-166), do que em Espírito da utopia, uma vez que Jó já apoia a dúvida divina, uma dúvida que, tendo em vista a guerra, era da mais alta atualidade. À apresentação da história na Bíblia, Bloch acrescenta que ela foi limpada (bereinigt), pois 'Jó deveria trazer os céticos de volta para o estábulo' (1985, p. 160). Ele mesmo se refere à rebelião de Jó contra um Deus injusto, sem com isso indicar que a injustiça no mundo seria uma simples prova de que Deus não existe, mas, muito antes, na direção 
de que no mundo sempre de novo existe uma saída, a qual conduz para fora do status existente, e uma esperança, que se alia à indignação, sim, uma que se funda nas possibilidades concretamente dadas de um novo ser (Bloch, 1985, p. 160).

Do que aqui, portanto, não se duvida de modo algum, é da necessidade sempre renovada do êxodo, segundo o qual o processo histórico como um todo é interpretado: como um acontecimento messiânico (messianisches Geschehen). E também o 'ser de Deus' é visto como um tal processo, e não como algo que existia imutável desde o início. Também a história do êxodo, no qual o próprio Deus afirma "Eu serei aquele que serei" (Êxodo, 3: 14), provaria justamente o contrário. Javé é um Deus em devir, sendo que - como afirma Bloch (1985, p. 125) no Ateísmo no cristianismo - "ele próprio ainda não é, se sabe enquanto uma promessa e, na melhor das hipóteses, cumprindo sua palavra, é futurístico como nada mais". O êxodo corresponde ao pensamento da libertação da servidão, torna palpável o profético e rebelde da Bíblia, pois essa é a "tônica que ela jamais perdeu" (Bloch, 2006, p. 52). Dentre outras coisas, aqui Bloch recorre ao pensamento de um 'comunismo de amor' (Liebeskommunismus) contido no cristianismo, o qual já poderia ser sentido no Antigo Testamento, uma vez que as "lembranças de um comunismo primitivo" teriam surgido no olhar retrospectivo ao tempo dos beduínos, no qual não teria havido diferença entre rico e pobre.

Mesmo afirmando que só teria sido aproximado tardiamente da filosofia judaica, por Tona Gehnert na época em que era estudante em Würzburg, Bloch reconhece no cristianismo a tradição messiânica, atuante e duradoura do judaísmo, e em relação à qual já em 1911 se autoidentificava como herdeiro da tradição messiânica. Nesse sentido, escreve para a judia crente Margarete Susman: "O melhor e mais autêntico do espírito judaico perpassou por Moisés, os profetas e a chassidim e, agora, se encarnou no meu manuscrito" (Bloch, apud Raulet, 2019, p. 124). O referido manuscrito ele abandonou mais tarde. Mesmo assim, naquela época, lhe foi atribuído, maliciosamente, por exemplo, por Marianne Weber, de que se via e se apresentava a si mesmo como precursor do Messias. Não por último, o tema da religião the foi trazido para mais próximo por sua esposa tardia, a baronesa báltica Elsa von Stritzky, que conhecera em 1911 e com a qual se casou em 1913, e que era uma cristã evangélica profundamente devota. A ela ele dedica as duas primeiras edições de sua principal obra elaborada no seu espírito expressionista chamada Espírito da Utopia, a qual inicia com uma crítica à guerra, ao capitalismo, ao prussianismo, e se amplia para uma crítica geral à "época da distância de Deus". Nessa obra o destino de Israel não se torna mais claro apenas no plano redentor do Velho Testamento e sim, de modo ainda mais forte, na história do cristianismo, 
onde, seja mais uma vez enfatizado, com cristianismo Bloch nunca quer dizer o cristianismo representado nas grandes igrejas.

Além disso, ele segue o filósofo da religião, senão teólogo, o judeu Martim Buber, mesmo que mais tarde simplesmente negue veementemente a sua influência. Em 1911, no seu terceiro discurso sobre o judaísmo, Buber havia dito: "O que no cristianismo é criativo, não é cristianismo, e sim judaísmo, e para tanto não precisamos procurar muito, apenas precisamos reconhecer e nos apossar disso em nós, pois isso carregamos cativo dentro de nós" (Buber, 2007, p. 247 ss.). No Princípio Esperança, Bloch descreve essa posse como esperança utópicomessiânica e nela Moisés e Jesus estariam unidos pelo espírito utópico. Em Moisés encontra o 'arquétipo-êxodo' (Exodus-Archetyp), “com rebelião, pela retirada do Egito” (Bloch, 2006a, p. 316), não com conteúdos finais já prontos, e sim com a promessa de um $U$-Topos, um não lugar, no qual corre leite e mel. Por isso, no item "Moisés ou a consciência da utopia na religião, da religião na utopia" (Bloch, 2006a, p. 318), é enfatizado especificamente o significado bíblicoprocessual (Biblisch-Prozesshaften):

Ehie asher ehie. "Eu sou aquele que é", um nome que, apesar de sua ambiguidade e de seu caráter de interpolação, revela a intenção de Moisés e não a encobre. A autodesignação de Javé é ambígua porque o verbo haia, que está na raiz de ehie, pode significar tanto "ser" quanto "devir", e é interpolada porque somente a teologia mais tardia poderia ter colocado essa palavra enigmática no lugar da palavra "Javé", proibida de pronunciar. Apesar disso, nessa passagem o acréscimo é autóctone, ou seja, interpreta uma intenção real, a mesma que fez com que o deus local, do Sinai, se pusesse em movimento rumo ao futurum chamado Canaã, rumo à pátria (Heimat) distante (Bloch 2006a, p. 319).

Se o futuro pertence ao que há de ser criado por Deus, então fica claro que já a história-êxodo indica que se trata de um reino de Deus entre os homens, de um impulso de libertação ou, dito de outro modo, de um transcender sem transcendência. Por isso Bloch gosta de citar Isaías 46 como sendo um indicativo de que para esse Deus se trata de tornar habitável a terra no aquém.

É na história-êxodo que nasce a ideia-messias, embora sua efetivação ainda esteja pendente. Essa é a essência do Antigo Testamento e, desse modo, a força judaica movente a dar continuidade ao desenvolvimento histórico. Também para Bloch, Jesus não é o Messias real, entretanto, é aquele através do qual a latência da esperança messiânica adquire significado 
enfático, uma vez que, por meio de Jesus, as ideias da justiça e da liberdade teriam sido levadas adiante $^{6}$. De modo algum Bloch duvida da historicidade de Jesus:

\begin{abstract}
Ao mesmo tempo, a estrebaria é de verdade; não se inventa uma origem tão modesta para um fundador. A saga não é capaz de pintar a miséria e, com certeza, não pintaria uma que se prolongasse por toda a vida. A estrebaria, o filho do carpinteiro, o entusiasta que se mistura com os pequenos, o cadafalso no final: tudo isso provém de material histórico e não do material dourado preferido pela saga (Bloch, 2006a, p. 340).
\end{abstract}

Se essa argumentação é adequada, fica aqui em aberto, decisivo, no entanto, permanece que Bloch indica para Jesus de Nazaré como sendo um tipo revolucionário, de que para ele se tratava de libertação e, por isso, o seu reino que se aproxima não poderia ser um reino do além, mas sim um reino a ser realizado entre seres humanos sobre a terra. Heiko Hartmann chama atenção para isso, indicando que Bloch via em ações como a limpeza do templo, ou expressões como "Eu não vim para trazer a paz, mas sim a espada", provas de que o Jesus histórico entendia a sua missão como libertação terrena. Até mesmo a teoria da trindade é interpretada por Bloch como sendo uma prova para tanto:

A trindade [...] definitivamente traz o Deus transcendente de volta para a terra e para os homens, na medida em que ela deixa emergir Deus no ser humano Jesus: 'Portanto, o filho ocupou o lugar do pai e quem olha para Jesus vê o Deus que é um ser humano. [...] Um ser humano ocupa o lugar da transcendência' (Bloch, 1985f, p. 480; cf. 2006a, p. 376).

"Jesus se torna o preparador do caminho do devir humano dos humanos, cuja essência ultimativa ainda há de ser liberada no futuro" (Hartmann, 2012, p. 43). Que a ortodoxia eclesiástica não interprete Jesus assim Bloch considera como sendo a tentativa consciente de negar o Jesus real. Paulo teria estilizado posteriormente a morte de Cristo em uma morte sacrificial (Opfertod). Para o filósofo, no entanto, o filho destrona o pai, e a designação de 'filho dos homens' se sobrepõe à de 'filho de Deus':

Onde uma criança ultrapassa assim, fica difícil para o pai manter-se ao lado da mesma. O corpóreo é tratado como coisa secundária, quase José foi negado, a luz fecundou desde cima. Mas também o pai celestial aparece poucas vezes ao lado do filho, ele não está mais solitário no trono. Na medida em que Jesus é acreditado enquanto mediador de Javé, ele se aproxima mais do que aquele, sim, ele o afasta (Bloch, 1985, p. 191).

6 Isso foi indicado especialmente por Joachim Perels (2008, p. 34 ss.) em seus apontamentos sobre as visitas a Ernst e Karola Bloch.

\begin{tabular}{|l|l|l|l|l|}
\hline Q Rovista Dialectus & Ano 10 & n. 21 & Janeiro - Abril 2021 & p.69-83 \\
\hline
\end{tabular}


A interpretação da figura de Jesus empreendida por Bloch é marcada por sua preferência por tipos utópicos. No caso do cristianismo, são os hereges (Ketzer) que mais lhe interessam, pois o fato de criar hereges é, para ele, o que há de melhor na religião (Cf. Bloch, 1985, p. 23). Nessa medida, portanto, também pôde apresentar seu livro sobre o herético Thomas Münzer, como sendo a apresentação de uma teoria e não como sendo simples teologia da revolução. Não por último, também sua filosofia pôde ser caracterizada por levar adiante aquilo que ainda não foi liquidado (das Unabgegoltene ${ }^{7}$ ) nos pensamentos que já passaram. Mas o quê, afinal, é aquilo que ainda não foi amortizado?

Em sua enciclopédia mais ou menos detalhada das esperanças humanas, para Bloch, trata-se sempre da questão de qual excedente está contido no objeto e de como poderia ser possível fazer com que esse excedente não permaneça externo ao sujeito. Isso, para ele, é também sempre um questionamento ao sujeito do presente, pois o efeito depende da atitude do sujeito em relação ao futuro: como o passado pode se tornar uma memória cultural que esteja em uma relação tão estreita com a experiência de vida individual a ponto de que o sujeito reconheça um comprometimento com os conteúdos virulentos, subversivos e ainda válidos do passado? Do passado, portanto, interessa fundamentalmente a expectativa do futuro, pois mesmo que o passado não possa mais ser modificado, isso não quer dizer que, por isso, a história já esteja feita. Algo desafiador lhe permanece inerente, algo que instiga o ser humano a lembrarse reflexivamente e, da mesma forma reflexiva, antecipar aquilo que ainda não foi liquidado (das Unabgegoltene vorwegzunehmen).

Com isso o não-mais e o ainda-não estão em conexão e somente por essa conexão é que se viabiliza um acesso dialético ao processo do mundo (Weltprozess). Nela, entretanto, há sempre também um comprometimento, um chamamento à responsabilidade dos seres humanos. Somente porque esse processo dos seres humanos e do mundo ainda é inconcluso, por ainda ser indeterminado e aberto, é que "tantos de seus possíveis rostos já puderam aparecer no plano sócio-histórico e ainda haverá outras tantas novas definições no futuro” (Bloch, 2006a,

\footnotetext{
7 Das Unabgegoltene é, por vezes, traduzido por "aspecto não anulado" (como em Bloch, 2005, p. 164), ou então como "não-cumprido" (Bloch, 2006a, p. 369), ou mesmo como "não resolvido" e "não quitado". O termo abgegolten, que pode ser traduzido por compensado (Ex.: cheque compensado), ao ser negado com o prefixo Un, também indica que unabgegolten poderia ser traduzido por "não compensado", daí preferirmos o termo "não liquidado" por nos parecer, mesmo não equivalendo totalmente, em algumas passagens ser o termo com sentido mais aproximado. Importa que fique claro que se trata de algo que não perdeu a validade, de algo que ainda carrega em si potenciais a serem realizados. Manteremos o termo entre parênteses no original a fim de não causar dúvidas (N.T.).
}

\begin{tabular}{|c|c|c|c|c|}
\hline Qevista Dialectus & Ano 10 & n. 21 & Janeiro - Abril 2021 & p. $69-83$ \\
\hline
\end{tabular}


p. 13), escreve Bloch no Princípio Esperança. Esses rostos, imagens e possibilidades desafiam os seres humanos e são [e assim ele explica o conceito 'não liquidado' ('unabgegolten')] progressivamente comprometedores, ou seja: comprometimento com o avanço da formação humana, da história e do mundo.

É nesse sentido que interpreta o papel de Thomas Münzer, concluindo que "Münzer, juntamente com todos os chiliastas, permanece chamador (Rufer) nessa peregrinação tempestuosa" (Bloch, 1985d, p. 241). Por detrás disso, conforme mostrou Micha Brumlik, se evidencia o pensamento de que o ser humano é marcado pela busca de uma vida em liberdade e livre de sofrimento. Mostra-se também que esse desejo se articula "na semântica da tradição judaico-cristã” (Brumlik, 2015, p. 21) fazendo com que Münzer se torne, então, um símbolo "para aquilo que as revoluções sempre buscaram, mas que, por motivos sistemáticos, nunca puderam realizar" (2015, p. 30).

Para Bloch, Münzer pertence sobremaneira àqueles que o motivaram a se dedicar ao 'não liquidado' na religião (Unabgegoltenen der Religion), pois, conforme Beat Dietschy (2019, p. 84), no livro sobre Münzer, “o apocalíptico esboça menos a transitoriedade desse mundo e muito mais o espaço no qual Bloch considera a convergência entre religião e revolução como algo possível”, sendo que o específico desse livro seria que nele se busca primeiramente uma vontade revolucionária de origem religiosa. "O que Bloch descobre em Münzer é, portanto, muito mais do que um espírito rebelde, ele vê nele também um teólogo que revoluciona a teologia" (Dietschy, 2019, p. 86).

Em Bloch, apocalipse não significa apenas o fim do mundo, mas significa sempre também processamento de uma crise, ele mostra o que está se findando na violência imperial e abre o olhar para a intencionada 'Nova Jerusalém'. Dietschy interpreta a apresentação de Bloch do apocalipse em consonância com o apocalipse religioso original, ou seja, como estágio de passagem: "enquanto algo que, assim como o chiliasmo, pertence ao mundo e não o abandona" (Dietschy, 2019, p. 103). Münzer é, segundo Bloch, um prospector (Sucher) do incondicionado sobre a terra, e nisso consistiria o significado para a sua filosofia da esperança.

Nele, entretanto, também já está contido o pensamento de que, para serem reconhecíveis como "possibilidades reais", as esperanças do futuro necessitam de uma análise histórico-social. Isso, simultaneamente, também significa que a filosofia da esperança de Bloch é marcada por uma reflexão explícita sobre decepções e rupturas. A história mundial é lida como uma documentação de esperanças abatidas, na qual, mesmo que em alguns momentos 
surja libertação, as esperanças são decepcionadas muito mais vezes. Entretanto, Bloch não toma essas decepções como evidências contra a esperança, mas as concebe como eventos que deixam marcas, porque justamente nelas é que é reconhecível aquilo que ‘ainda não está liquidado' (das Unabgegoltene). É na sua relação com o futuro que se define se algo é relegado diretamente para o esquecimento ou se se torna motivo para uma lembrança ativadora. Assim como na Bíblia, a lembrança necessita da expectativa de futuro, só assim ela indica para o que 'não está liquidado' (das Unabgegoltene), cuja implementação ainda está em aberto.

Sem causar prejuízo ao que foi dito, nunca é de se negar que a compreensão de religião de Bloch é tal que ele não precisa de um senhor acima do mundo. Ele apenas procura o espírito das utopias justamente também pelo recurso às figuras de pensamento da escatologia judaico-cristã - cujo funcionamento ele inverte em benefício da autorredenção da humanidade no final dos tempos. Crença e racionalidade para ele não são contrastantes, o que faz dele um desses filósofos que reconhecem na experiência religiosa algo que não pode simplesmente ser ignorado, pois, se assim fosse, se recusaria o olhar para com as imagens de esperança que se tornam especialmente claras na apocalíptica judaico-cristã, como no chiliasmo joachimniano (joachimitischen Chiliasmus), nas ideias sociorrevolucionárias de Thomas Münzer e de muitos outros.

Por isso, segundo Henning Tegtmeyer, Bloch recorre

\begin{abstract}
à figura da escatologia no pensamento judeu e cristão, inclusive à história das suas respectivas heresias. Interpreta a ideia da escatologia de modo tão subversivo quanto a ideia da autorredenção da humanidade, a qual, segundo sua convicção, encontraria sua expressão mais clara no pensamento herético. [...] Porém, essa antropologia somente se torna compreensível através da sua inserção em um materialismo especulativo e, com isso, numa ontologia e cosmologia geral, que compreende o ser humano como sendo o mais belo florir do processo natural. Com essa ampliação da antropologia para a metafísica, Bloch reclama para si a herança do pensamento aristotélico, tomista e schellinguiano (2013, p. 21).
\end{abstract}

Tegtmeyer critica os esforços de Bloch de esclarecer "todos os fenômenos da consciência religiosa e da vida sem a 'hipótese Deus', ou seja, de modo completamente ateísta" (2013, p. 21). Bloch, no entanto, sempre de novo reafirmará essa sua posição. E é assim que se encontra, tanto no Ateísmo no cristianismo quanto no Princípio Esperança a frase 'Onde há esperança, há religião'. No entanto, no seu discurso do Dia do Estudante, na Comunidade de Novos Estudantes Católicos, [e não só aí!], ele acrescenta: 
[...] de que essa frase não pode ser invertida sem mais. Onde há religião sempre também há esperança. Mas onde há esperança há sempre também religião. As histórias das religiões mostram exuberâncias tremendas de esperança, dimensões de esperança que em nenhum outro lugar surgem com tanta completude. Brilho, fantastiquices de uma fantasia autêntica e gigantescas antecipações, carregadas de imagens de esperança, adentrando no invisível como sendo o ainda-não-visível, o que ainda não se tornou. Nesse gigantesco diante-de-nós (Vor-Uns), e que assim também consta na teoria dos desejos de Feuerbach, foi lançado para adiante a partir de nós, e vem ao nosso encontro de tal forma que as propriedades de Deus são modelos para nós humanos, o de cima é algo que está à nossa espera (Bloch, 1993, p. 26).

Para Bloch, portanto, se trata da comprovação de que justamente também a religião testemunha que o ser humano, juntamente com o mundo, está em processo. De que também na religião, assim como em todos os outros sonhos de uma vida melhor, se manifesta a esperança por um definitivo novo-bom (Gutes-Neues).

Para Bloch o ser humano é sempre um ser esperançoso, que padece junto à inconclusão do mundo e, justamente por isso, desenvolve modelos de um mundo que deu certo. Entretanto, adverte:

O amanhã vive no hoje e sempre se está perguntando por ele. Os rostos que se voltaram na direção da utopia foram, é verdade, diferentes em cada época, exatamente como aquilo que eles imaginaram ver nela no que diz respeito aos detalhes, de caso por caso. Em contrapartida, a direção é parecida em toda parte, sim, é a mesma quanto ao seu alvo ainda encoberto; ela se manifesta como a única coisa inalterável na história. Felicidade, liberdade, não alienação, idade de ouro, terra que emana leite e mel, o feminino eterno, o sinal da trombeta no Fidélio e o cristomórfico do dia da ressureição que se seguiu: são tantos e de peso tão diverso os testemunhos e as imagens, mas todos estão postados em torno daquilo que fala por si mesmo, enquanto ainda está calado (Bloch, 2006a, p. 462).

O conceito de novo [ele fala de 'novum'] Bloch toma da escatologia cristã, portanto, promessa de um novo céu e de uma nova terra. Se volta contra todo 'pensar desde as origens' (Ursprungsdenken), uma vez que o novum, por causa da sua relação total com o conteúdo final, se volta para uma "fidelidade ao início" que "ainda terá a sua gênese" (Bloch, 1985e, p. 376). Daí o novum ser uma categoria que Bloch põe em relação com a de front e a de ultimum. $\mathrm{O}$ front é o recorte temporal na vida humana, no qual o novo emerge, algo como o obscuro do instante vivido. Um tal instante, porém, precisa ser percebido, o que também significa que ele pode ser perdido. O front é, ao mesmo tempo, o lugar no qual o ser humano se põe em relação com o futuro, e é apenas aqui que o pensar pode se tornar um transpor. E isso acontece quando o pensar leva em consideração os sonhos para adiante, portanto, não aqueles que se direcionam para o ar vazio, mas sim para a história e as possibilidades e tendências aí ancoradas. O instante 
não apenas precisa ser percebido, ele também precisa oferecer possibilidades reais para o novo. E o novum se volta para o ultimum, para a identidade entre essência e existência, que apenas se prefigura em instantes realizados (in erfüllten Augenblicken).

Também aqui se mostra o vínculo do pensamento de Bloch para com a tradição apocalíptica. E mais: que para ele não se trata de reencontrar um início perdido, mas sim, sempre, de um efetivo e verdadeiro novo. Verdadeiro novum é sempre uma tentativa de ultimum. Já nas primeiras páginas do Princípio Esperança está escrito:

[...] para que o novum realmente assim o seja, dele faz parte não só a oposição abstrata à repetição mecânica, mas até mesmo um tipo específico de repetição - a do conteúdo final total que ainda não se tornou realidade, referido e intencionado, tentado e processado nas novidades progressivas da história (Bloch, 2005, p. 200).

\section{Referências:}

BALL, Hugo. Die Umgehung der Instanzen. In: Freie Zeitung, 2. Jg., n. 92, 1918.

BLOCH, Ernst. Atheismus im Christentum. Zur Religion des Exodus und des Reichs. Werkausgabe Bd. 14. Frankfurt am Main: Suhrkamp, 1985.

BLOCH, Ernst. Bloch an Muehlon. In: BLOCH, Karola (Org.). Briefe 1903 bis 1975 . Frankfurt am Main, 1985a.

BLOCH, Ernst. Erbschaft dieser Zeit. Werkausgabe Bd. 4. Frankfurt am Main: Suhrkamp, 1985 b.

BLOCH, Ernst. Hoffen ohne Glauben (1966). In: WEIGAND, Karlhein (Org.). BlochAlmanach, v. 13, Baben Baden, 1993, p. 9-32.

BLOCH, Ernst. Geist der Utopie. Erste Fassung. Werkausgabe Bd. 16. Frankfurt am Main: Suhrkamp,ain 1985c.

BLOCH, Ernst. O Princípio Esperança, v. I. Tradução de Nélio Schneider. Rio de Janeiro: EdUERJ: Contraponto, 2005.

BLOCH, Ernst. O Princípio Esperança, v. II. Tradução de Werner Fuchs. Rio de Janeiro: EdUERJ: Contraponto, 2006.

BLOCH, Ernst. O Princípio Esperança, v. III. Tradução de Nélio Schneider. Rio de Janeiro: EdUERJ: Contraponto, 2006a.

BLOCH, Ernst. Thomas Münzer als Theologe der Revolution (TM). Werkausgabe Bd. 2. Frankfurt am Main: Suhrkamp, 1985d. 
BLOCH, Ernst. Tübinger Einleitung in die Philosophie. Werkausgabe Bd. 13. Frankfurt am Main: Suhrkamp, 1985e.

BLOCH, Ernst. Wozu der Beschäftigung mit dem biblischen Mythos. In: BLOCH, Ernst. Leipziger Vorlesungen. Werkausgabe Bd. 1. Frankfurt am Main: Suhrkamp, 1985f, p. 450452.

BRUMLIK, Micha. Ernst Blochs, Thomas Münzer - eine chiliastische Theorie der Revolution. In: VIDAL, Francesca (Hg.): Der Traum des Unbedingten. Bloch-Jahrbuch 2014/15. Würzburg: Königshausen u. Neumann, 2015, p. 11-30.

BUBER, Martin. Drei Reden über das Judentum (1911). In: BUBER, Martin. Frühe jüdische Schriften. Werkausgabe 3. Gütersloh: Güitersloher Verlaghaus, 2007, p. 219-256.

DIETSCHY, Beat. Auf dem Sprung zum Niegewesenen. Zur Apokalyptik in Blochs MüntzerBuch. In: VIDAL, Francesca (Org.): Fremdes Zuhause, urvertraute Fremde. Zur aktuellen Debatte über, Fremd und Eigen' aus Blochscher Perspektive. Würzburg: Königshausen u. Neumann, 2019, p. 83-108.

HARTMANN, Heiko. Atheismus. In: DIETSCHY, Beat; ZEILINGER, Doris; ZIMMERMANN, Rainer E. (Org.): Bloch-Wörterbuch. Leitbegriffe der Philosophie Ernst Blochs. Berlin; Boston: De Gruyter, 2012.

KOCH, Gerd Koch. Heimat. In: DIETSCHY, Beat; ZEILINGER, Doris; ZIMMERMANN, Rainer E. (Org.): Bloch-Wörterbuch. Leitbegriffe der Philosophie Ernst Blochs. Berlin; Boston: De Gruyter, 2012, p. 168-189.

KRUTTSCHNITT, Elke. Ernst Bloch und das Christentum. Der geschichtliche Prozeß und der philosophische Begriff der, Religion des Exodus und des Reichs`. Mainz: Grünewald,1993.

MOLTMANN, J; METZ, J. B. Ernst Bloch und die Theologie (entrevista televisiva de 19.09.1967). In: WEIGAND, Karlhein (Org.). Bloch-Almanach 3. Folge 1983. Baden-Baden 1983.

(Disponível

em:

https://www.youtube.com/watch?v=T4oXNBm29jA\&list=PL5rv0LxqofNovSyM6unMo1O2 q6DyR4Fg-\&index $=14 \& \mathrm{t}=0 \mathrm{~s}$.

PERELS, Joachim. Aufzeichnungen über Besuche bei Ernst und Karola Bloch. In: Bloch Almanach. V. 27/2008.

RAULET, Gerard. Walter Benjamins Rezeption von Geist der Utopie und das jüdische Problem. In: BRUZZONE, Attilio et al. (Org.). Rivista Online de Filosofia, n. 5. Roma: 2019, p. 123-140.

TEGTMEYER, Henning. Gott, Geist, Vernunft: Prinzipien und Probleme der Natürlichen Theologie. Tübingen: Mohr Siebeck, 2013. 